\title{
Influência dos Parâmetros de Soldagem no Ensaio de Torção de Solda a Ponto em um Dispositivo Automatizado Recém Desenvolvido
}

\author{
Thales Lucas Diniz de Avila ${ }^{1}$, Alexandre Queiroz Bracarense ${ }^{1}$ \\ 1 Universidade Federal de Minas Gerais - UFMG, Programa de Pós-Graduação em Engenharia Mecânica, Belo Horizonte, MG, \\ Brasil.
}

Recebido: 19 Mar., 2017

Aceito: 9 Ago., 2017

E-mail: thalesdavila@gmail.com (TLDA)
Resumo: O principal processo de união de chapas em veículos é a soldagem por resistência elétrica a ponto (RSW - Resistance Spot Welding). Quando em trabalho os pontos de solda da estrutura do veículo sofrem esforços de tração, cisalhamento e torção, possuindo menor resistência ao esforço de torção. A correta caracterização da robustez da junta soldada é de extrema importância para garantia da segurança do veículo. Por isso é fundamental o domínio da reação aos esforços, para o correto dimensionamento do ponto. Para o esforço de tração e cisalhamento, são utilizados ensaios com modo de falha e relação entre parâmetros e esforços bem conhecidos. Para o ensaio de torção, recentemente foi proposto um equipamento automatizado, compacto e de simples manuseio. Portanto, o objetivo deste trabalho é avaliar influência dos parâmetros: tempo e corrente de soldagem no resultado do ensaio. Foram soldados corpos de prova com 0,91mm de espessura mantendo a corrente em 4,25kA, 5,0kA e $5,75 \mathrm{kA}$ e variando o tempo de soldagem em 10, 30, 50, 70 e 90 ciclos. Os ensaios demostraram uma grande influência da corrente de soldagem na curva característica do ensaio de torção, fenômeno que não se repetiu para o tempo de soldagem.

Palavras-chave: Soldagem a ponto; Resistência a torção; Parâmetros de soldagem.

\section{Influence of Welding Parameters on the Spot Weld Torsion Test on a Newly Developed Automated Device}

\begin{abstract}
The main process of joining plates in vehicles is Resistance Spot Welding. When in work the spot weld of the vehicle structure suffer tensile, shear and torsional stresses having less resistance to torsion. The correct characterization of the strength of the welded joint is of extreme importance to guarantee the safety of the vehicle. It is fundamental knowing the reaction to the efforts for the correct design of the point. For strength and shear stress, tests are used with known failure mode and relationship between parameters and stresses. For the torsion test, automated, compact and simple handling equipment has recently been proposed. Therefore, the objective of this work is evaluate the influence of the parameters: time and welding current in the test result. It was welded with specimens of $0.91 \mathrm{~mm}$ thickness, maintaining the current at $4.25 \mathrm{kA}, 5.0 \mathrm{kA}$ and $5.75 \mathrm{kA}$ and varying the welding time at 10 , 30, 50, 70 and 90 cycles. The tests showed a great influence of the welding current on the torsion test characteristic curve, a phenomenon that was not repeated for the welding time.
\end{abstract}

Key-words: Spot welding; Torsion resistance; Welding parameters.

\section{Introdução}

O processo de soldagem por resistência elétrica a ponto (RSW) é utilizado em diversas áreas da indústria e em grande escala na indústria automotiva. Este fato se deve a alta produtividade, pouca necessidade de experiência do operador, baixo custo operacional e facilidade de automatização se comparado a outras técnicas de união. Outras vantagens são a não utilização do metal de adição, possibilidade de soldar formas complexas e menores ZTA se comparado aos processos a arco. As dificuldades que o processo apresenta são: dificuldade da otimização dos parâmetros de soldagem para obter propriedades mecânicas desejadas, aparência não satisfatória, alto custo do investimento em máquinas e grande demanda da rede elétrica. Por possuir uma difícil otimização dos parâmetros, a definição de valores que garantam propriedades desejadas de um ponto de solda é de extrema importância. Nos veículos modernos existem entre 2000 e 5000 pontos de solda sendo que de $20 \%$ a $30 \%$ destes pontos possuem uma incerteza com relação à qualidade. Para
Este é um artigo publicado em acesso aberto (Open Access)
sob a licença Creative Commons Attribution Non-Commerci que permite uso, distribuição e reprodução em qualquer meio, sem restriçōes desde que sem fins comerciais e que 0 trabalho original seja corretamente citado. 
aumentar a confiabilidade do processo é demandado um custo para "extra solda" que não seria necessária se fosse dominado todos os parâmetros que influenciam nas propriedades mecânicas [1].

No processo de soldagem por resistência as chapas são unidas através da fusão do material resultante do calor gerado pela resistência elétrica entre as chapas quando estão unidos pela força dos eletrodos. A quantidade de calor gerada depende de três principais parâmetros, a corrente, a resistência elétrica do condutor e a duração da corrente descrevendo o Efeito Joule [2-4].

$$
Q=I^{2} R t
$$

Onde $Q$ é o calor gerado [J], I a corrente elétrica [A], R a resistência do condutor [ $\Omega$ ] e t o tempo de aplicação da corrente [s].

Analisando a Equação 1 infere-se que o calor gerado é diretamente proporcional à resistência elétrica do material, ao tempo de soldagem e ao quadrado da corrente [5]. Os três principais parâmetros de soldagem são: Corrente de Soldagem, Tempo de Soldagem e Força. O tempo de soldagem compreende o intervalo através do qual a corrente flui pelo circuito. Nesta etapa, a corrente de soldagem aquece e funde o material, formando o ponto de solda [4]. A força de soldagem é responsável pela determinação da resistência elétrica de contato, influenciando diretamente na quantidade de calor gerado na formação do ponto.

Os parâmetros de soldagem influenciam diretamente nas características geométricas do ponto de solda e por consequência em sua resistência mecânica. Para o aumento do tempo de soldagem ou para o aumento da corrente de soldagem ocorre o aumento do diâmetro do ponto de solda e por consequência o aumento da resistência mecânica até um limite que ocorre a expulsão de material. Devido à maior identação e a perda de material a resistência mecânica não continua aumentando [1]. A força do eletrodo deve ser suficiente para conter o metal fundido dentro dos parâmetros dimensionais do eletrodo, ou seja, não pode ser baixa, pois pode provocar a expulsão do material, nem alta que diminua a resistência de contato, diminuindo o calor gerado [4].

Para a caracterização do ponto de solda e a definição de qual é a influência dos parâmetros de soldagem nos esforços solicitados são realizados ensaios mecânicos. Os ensaios mais difundidos são o de Tensão Cisalhante e Tração Axial, para ambos o ensaio é realizada em uma máquina de tração até o rompimento do ponto e determinado a carga máxima de ruptura. No ensaio de Tensão Cisalhante com o aumento do tempo e corrente de soldagem ocorre o aumento da resistência do ponto de solda como mostra a Figura 1 [1].

Recentemente, foi desenvolvido um dispositivo automatizado, capaz de realizar ensaios de torção de forma rápida e simples, utilizando o mesmo corpo de prova de um ensaio de tensão cisalhante convencional, sendo que este equipamento unido a metalografia contribui para detectar até $99 \%$ dos defeitos de uma solda a ponto.
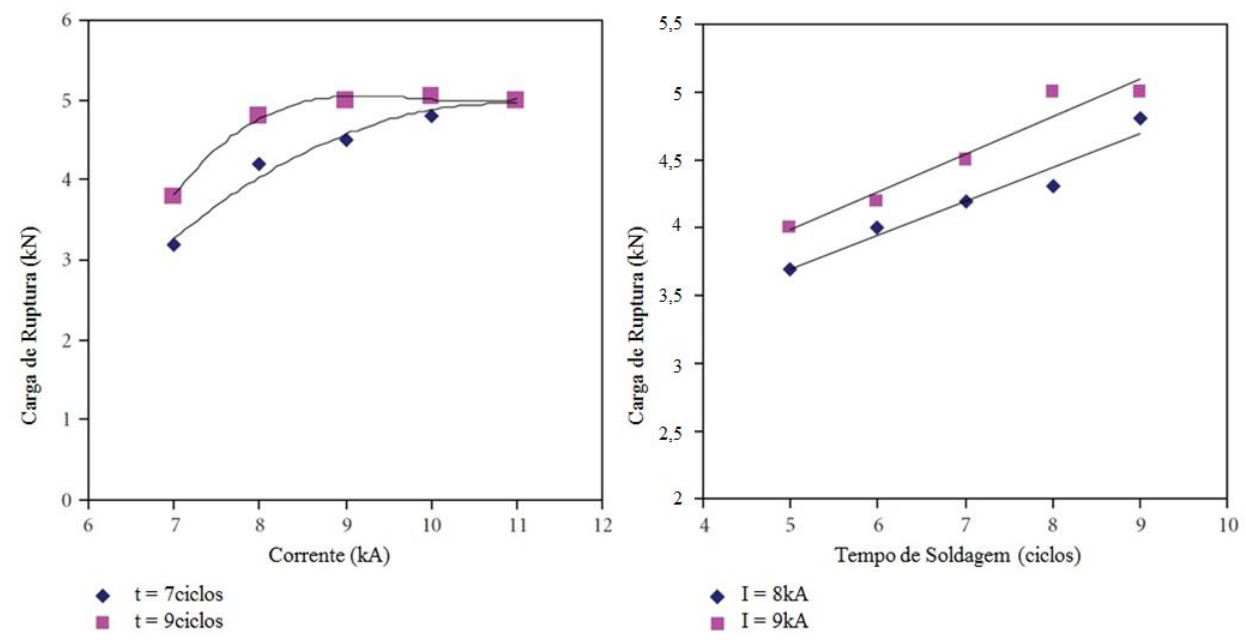

Figura 1. Influência dos parâmetros de soldagem na carga de [1]. 
Para teste do equipamento foi realizado a comparação com o ensaio de tração obtendo, para dois parâmetros de soldagem, uma diferença entre eles de $11 \%$, já para o recente ensaio de torção $6 \%$ demostrando a coerência dos resultados do ensaio [6]. Os testes preliminares com o monitoramento de tensão do motor durante todo o ensaio demostraram grande potencial para análise do esforço de torção em solda a ponto. 0 equipamento permite grande flexibilidade na realização do ensaio de torção uma vez que é compacto e os corpos de prova são de fácil confecção sendo uma inovação na realização do ensaio de torção.

O objetivo deste trabalho é através da realização de corpos de prova soldados, variando corrente e tempo de soldagem, avaliar a influência dos parâmetros de soldagem na resistência mecânica a torção do ponto de solda, utilizando o equipamento de torção recém-desenvolvido.

\section{Materiais e Métodos}

Neste trabalho foi utilizado um aço comum baixa liga SAE 1015 com revestimento Galvalume ${ }^{\circledR}$ e espessura de $0,91 \mathrm{~mm}$. Os corpos de prova foram cortados com $138 \mathrm{~mm}$ de comprimento e $60 \mathrm{~mm}$ de largura e sobrepostos em 45mm atendendo a norma AWS/SAR D8.9:2002 utilizada para ensaios de Tensão cisalhante. Antes dos ensaios os corpos de prova foram limpos e desengordurados utilizando solvente tolueno.

Para a soldagem foi utilizado uma máquina com transformador convencional com a frequência da rede de $60 \mathrm{~Hz}$, alimentação $440 \mathrm{~V}$, potência nominal de 54KVA e potência permanente de 38KVA com um controlador convencional da marca Fase, modelo Weld $334 \mathrm{~m}$ e um sistema de refrigeração externo individual. A pinça é também do fabricante Fase modelo X/4-200, manual, de forma construtiva " $X$ " com acionamento pneumático. Os eletrodos utilizados atendem a Classe 20 da norma RWMA.

Para validação dos parâmetros foram confeccionados 45 corpos de prova sendo 3 para cada parâmetro apresentado na Tabela 1. Para cada parâmetro um corpo de prova foi utilizado no ensaio de torção, um corpo de prova para o ensaio de ultrassom e outro para metalografia.

Tabela 1. Parâmetros utilizados.

\begin{tabular}{|c|c|c|c|c|c|c|}
\hline IDENT. & QUANT. & $\begin{array}{l}\text { CORRENTE DE } \\
\text { SOLD. (kA) }\end{array}$ & $\begin{array}{l}\text { TEMPO DE } \\
\text { SOLD. (Ciclos) }\end{array}$ & $\begin{array}{c}\text { PRESSÃO } \\
\text { (daN) }\end{array}$ & $\begin{array}{c}\text { ESP. CHAPA } 1 \\
(\mathrm{~mm})\end{array}$ & $\begin{array}{c}\text { ESP. CHAPA } 2 \\
(\mathrm{~mm})\end{array}$ \\
\hline 1.1 .2 .25 & 3 & 4,25 & 10 & 350 & 0,91 & 0,91 \\
\hline 1.2 .2 .25 & 3 & 4,25 & 30 & 350 & 0,91 & 0,91 \\
\hline 1.3.2.25 & 3 & 4,25 & 50 & 350 & 0,91 & 0,91 \\
\hline 1.4.2.25 & 3 & 4,25 & 70 & 350 & 0,91 & 0,91 \\
\hline 1.5.2.25 & 3 & 4,25 & 90 & 350 & 0,91 & 0,91 \\
\hline 2.1 .2 .25 & 3 & 5 & 10 & 350 & 0,91 & 0,91 \\
\hline 2.2.2.25 & 3 & 5 & 30 & 350 & 0,91 & 0,91 \\
\hline 2.3.2.25 & 3 & 5 & 50 & 350 & 0,91 & 0,91 \\
\hline 2.4.2.25 & 3 & 5 & 70 & 350 & 0,91 & 0,91 \\
\hline 2.5.2.25 & 3 & 5 & 90 & 350 & 0,91 & 0,91 \\
\hline 3.1 .2 .25 & 3 & 5,75 & 10 & 350 & 0,91 & 0,91 \\
\hline 3.2.2.25 & 3 & 5,75 & 30 & 350 & 0,91 & 0,91 \\
\hline 3.3.2.25 & 3 & 5,75 & 50 & 350 & 0,91 & 0,91 \\
\hline 3.4.2.25 & 3 & 5,75 & 70 & 350 & 0,91 & 0,91 \\
\hline 3.5.2.25 & 3 & 5,75 & 90 & 350 & 0,91 & 0,91 \\
\hline
\end{tabular}

O ensaio de ultrassom foi utilizado para validar as características do ponto de solda, para isso foi utilizado o equipamento RSWA (Resistance Spot Weld Analyzer) da marca Tessonics que é capaz de construir imagens de no máximo $10 \mathrm{~mm}$ de diâmetro. A análise metalográfica foi utilizada para verificação do ultrassom e determinação das dimensões geométricas do ponto. Para a metalografia foi realizado um corte transversal no corpo de prova soldado, que foi embutido em baquelite, lixado com as lixas de granulometria 80, 220, 400, 600 e 1200 depois polido com alumina de $1 \mu$, ataque químico com Nital $2 \%$ e realizado as imagens. 
Influência dos Parâmetros de Soldagem no Ensaio de Torção de Solda a Ponto em um Dispositivo Automatizado Recém Desenvolvido

Foram realizados mais 45 corpos de prova, apenas para ensaio de torção, com os mesmos parâmetros utilizados anteriormente. O Ensaio de Torção foi realizado no equipamento recém-desenvolvido demonstrado na Figura 2. O equipamento é acionado por um motor elétrico BOSCH do tipo FPG, modelo 0130821979 de tensão nominal de $24 \mathrm{~V}$ e $11,6 \mathrm{~W}$ de potência. Para alimentação do motor foi utilizado um fonte de alimentação DC simétrica digital da marca POLIMED modelo PMI 3005D capaz de fornecer até 30V de tensão e 5A de corrente. Nos testes foi utilizada uma tensão de 12V. Para a transmissão do movimento é utilizado um pinhão de 10 dentes acoplado em uma coroa de 68 dentes resultando em uma relação de transmissão de 1:6,8. Para mensurar o ângulo foi utilizado o medidor de inclinação da marca INSIZE modelo 2178-1 [6].
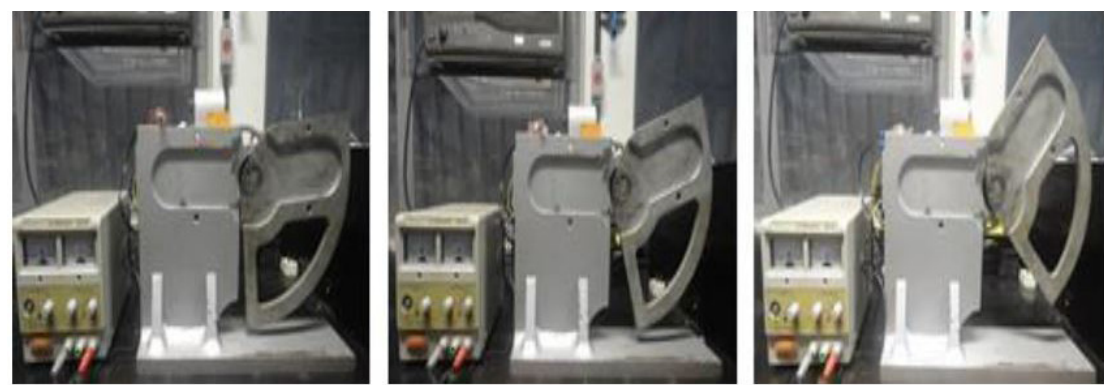

Figura 2. Funcionamento do dispositivo de torção [6].

O ensaio é realizado posicionando o corpo de prova soldado no dispositivo, posicionando o ponto de solda no centro de torção do dispositivo, iniciado a aquisição de dados, acionado o equipamento utilizando o interruptor manual. O ensaio ocorre com movimentação do motor que movimenta a parte móvel com a relação de transmissão já citada. Para a interrupção do ensaio é utilizado uma chave fim de curso no final da trajetória da parte móvel que totaliza 41ㅇ. É interrompida a aquisição de dados e o corpo de prova e retirado o corpo de prova do equipamento.

A aquisição de dados foi realizada monitorando a tensão de alimentação do motor, utilizando o equipamento IMC SAP V4Ti gerando a curva característica apresentada na Figura 3. A abscissa representa o tempo de ensaio em segundos e a ordenada a tensão de alimentação do motor. O programa de aquisição de dados gera um arquivo em formato .txt que foi inserido no programa Excel para que pudesse ser editado e avaliado diferentes ensaios no mesmo gráfico. Para facilitar a análise os dados foram tratados, através de uma média móvel entre 9 períodos, com isso foi possível absorver variações sazonais devido à alta taxa de aquisição de dados de $5000 \mathrm{~Hz}$. $\mathrm{O}$ ensaio tem uma peculiaridade, o torque resistivo aplicado no motor varia sendo difícil a sua mensuração direta. Desta forma uma variável que esta diretamente ligada ao comportamento do ensaio é a velocidade de torção que pode ser

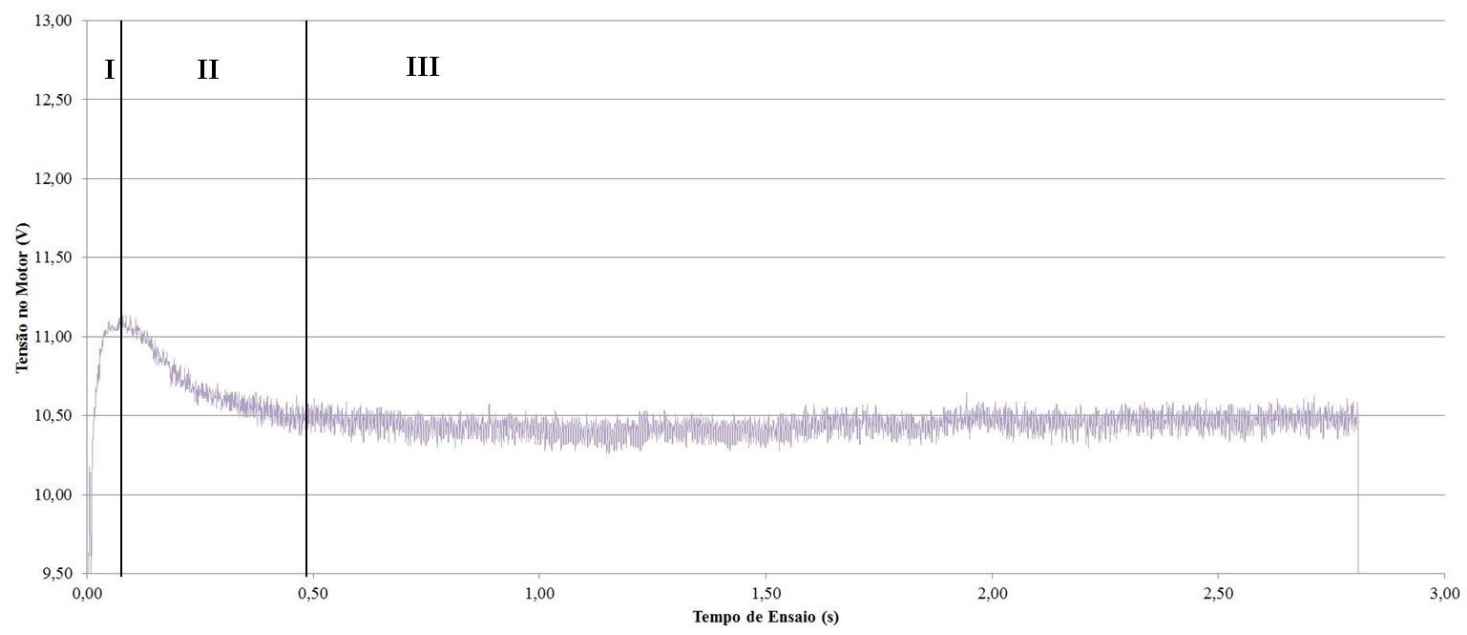

Figura 3. Curva característica do ensaio de torção instrumentado. 
relacionada à tensão de alimentação. Com a redução da velocidade ocorre a redução da tensão de alimentação. Com base na teoria dos motores elétricos de corrente contínua é possível identificar no ensaio três regiões principais [7]. A região "I" representa o início da alimentação do motor elétrico causando a movimentação do dispositivo, com aumento da velocidade do ensaio, ocorre o aumento da tensão do motor. A região "II" representa a resistência do ponto de solda ao movimento do dispositivo, com a diminuição da velocidade do ensaio ocorre a diminuição da tensão de alimentação do motor. A região "III" demostra a estabilização da tensão ou o movimento constante do dispositivo sem variação da velocidade.

\section{Resultados e Discussão}

Avaliando os corpos de prova utilizando o ensaio de ultrassom e metalografia foram identificadas as seguintes características apresentadas na Tabela 2. Para a chapa de 0,91 mm o diâmetro do ponto deve ser superior a 3,81mm e a identação deve ser de 0,091m a 0,273mm segundo a norma 9.50171 Fiat Automóveis. Além das dimensões geométricas do ponto de solda: diâmetro e identação, o diagnóstico do ultrassom pode apresentar diagnóstico como: ponto bom, ponto solto, ponto pequeno, ponto com defeito interno, ponto colado e ponto queimado. A caracterização de um ponto bom é feita observando a atenuação do sinal, a distância entre os ecos, que deve representar a espessura final do ponto de solda, e a linha inferior de ruído deve ser inferior a $10 \%$ de energia do

Tabela 2. Resultado do teste de validação dos parâmetros.

\begin{tabular}{|c|c|c|c|c|c|c|c|c|}
\hline \multirow[b]{3}{*}{$\begin{array}{l}\text { ㅇ } \\
\text { o } \\
\text { ㅇ } \\
\text { o } \\
\text { 은 }\end{array}$} & \multicolumn{2}{|c|}{ Parâmetros de Soldagem } & \multicolumn{5}{|c|}{ Variáveis Mensuradas } & \multirow[b]{3}{*}{ US } \\
\hline & \multirow[b]{2}{*}{ 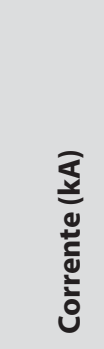 } & \multirow{2}{*}{ 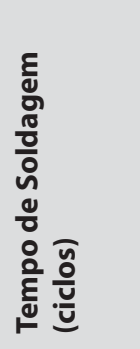 } & \multicolumn{3}{|c|}{ Diâmetro (mm) } & \multicolumn{2}{|c|}{$\begin{array}{c}\text { Identação (mm) } \\
\text { Chapa } 1 / \text { Chapa } 2\end{array}$} & \\
\hline & & & $\begin{array}{l}\text { 인 } \\
\sum^{\pi}\end{array}$ & 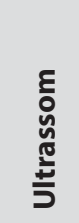 & 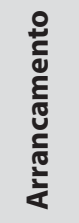 & $\begin{array}{l}0 \\
\text { 는 } \\
\sum^{\pi}\end{array}$ & 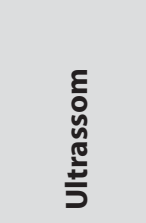 & \\
\hline 1.1.2.25 & 4,25 & 10 & 3,97 & 3,65 & 3,70 & $0,16 / 0,16$ & $0,06 / 0,06$ & COLADO \\
\hline 1.2.2.25 & 4,25 & 30 & 4,35 & 3,7 & 3,90 & $0,05 / 0,05$ & $0,07 / 0,08$ & COLADO \\
\hline 1.3.2.25 & 4,25 & 50 & 4,23 & 3,7 & 3,95 & $0,07 / 0,09$ & $0,08 / 0,1$ & COLADO \\
\hline 1.4.2.25 & 4,25 & 70 & 4,53 & 4 & 4,35 & $0,17 / 0,17$ & $0,1 / 0,12$ & COLADO \\
\hline 1.5.2.25 & 4,25 & 90 & 4,57 & 4,7 & 4,55 & $0,09 / 0,09$ & $0,08 / 0,12$ & COLADO \\
\hline 2.1 .2 .25 & 5,0 & 10 & 2,39 & 3,45 & 2,95 & $0,10 / 0,10$ & $0,08 / 0,09$ & COLADO \\
\hline 2.2.2.25 & 5,0 & 30 & 3,32 & 4,45 & 3,35 & $0,100 / 0,1$ & $0,09 / 0,08$ & COLADO \\
\hline 2.3.2.25 & 5,0 & 50 & 3,11 & 4,9 & 3,45 & $0,02 / 0,02$ & $0,09 / 0,11$ & COLADO \\
\hline 2.4.2.25 & 5,0 & 70 & 4,90 & 5,15 & 4,55 & $0,10 / 0,10$ & $0,05 / 0,12$ & COLADO \\
\hline 2.5 .2 .25 & 5,0 & 90 & 4,96 & 5,35 & 5,15 & $0,14 / 0,14$ & $0,11 / 0,13$ & COLADO \\
\hline 3.1 .2 .25 & 5,75 & 10 & 3,69 & 4,8 & 3,70 & $0,21 / 0,21$ & $0,08 / 0,08$ & BOM \\
\hline 3.2 .2 .25 & 5,75 & 30 & 4,80 & 4,5 & 4,75 & $0,33 / 0,33$ & $0,17 / 0,18$ & BOM \\
\hline 3.3.2.25 & 5,75 & 50 & 4,85 & 4,95 & 4,90 & $0,32 / 0,32$ & $0,19 / 0,1$ & BOM \\
\hline 3.4.2.25 & 5,75 & 70 & 4,93 & 5,45 & 4,85 & $0,34 / 0,34$ & $0,18 / 0,17$ & BOM \\
\hline 3.5.2.25 & 5,75 & 90 & 4,31 & 5,6 & 5,25 & $0,26 / 0,26$ & $0,12 / 0,18$ & BOM \\
\hline
\end{tabular}

eco maior. O ponto colado é caracterizado quando ocorrem apenas poucos pontos de fusão entre as chapas desta forma o ultrassom visualizará um grande número de ecos intermediários. Nos testes realizados estas foram as duas características identificadas. Avaliando as variáveis mensuradas individualmente, os pontos 1.1.2.25, 1.2.2.25, 1.3.2.25 e 2.1.2.25 na medida realizada via ultrassom não atendem aos requisitos de diâmetro mínimo do ponto $(3,81 \mathrm{~mm})$. Já para identação, em relação às medidas realizadas via ultrassom e macrografia simultaneamente, os pontos 3.5.2.25, 2.5.2.25 e 1.4.2.25 atendem a norma $(0,091 \mathrm{~mm}$ a $0,273 \mathrm{~mm})$. Assim como no ultrassom na 
Influência dos Parâmetros de Soldagem no Ensaio de Torção de Solda a Ponto em um Dispositivo Automatizado Recém Desenvolvido

metalografia foi possível constatar que com o aumento do tempo de soldagem e aumento do corrente de soldagem ocorre o aumento do diâmetro do ponto e é esperado o aumento da resistência mecânica.

Para os ensaios de torção foram selecionados todos os parâmetros da Tabela 2, mesmo os que apresentaram ponto colado, baixa identação ou diâmetro pequeno, pois o objetivo é avaliar a máquina de torção quando ensaiando corpos de prova com diferentes características, incluindo as situações de falha constatada.

A segunda rodada de testes foi utilizada para avaliar a influência da corrente e do tempo de soldagem na curva característica apresentada acima. Para isso foi plotado em um mesmo gráfico os testes para uma mesma corrente e diferentes tempo de solda. Com o aumento do diâmetro do ponto de solda é esperado um aumento da resistência mecânica do ponto, a resistência à torção do ponto causa a dificuldade de movimentação da parte móvel do dispositivo e por consequência a diminuição da velocidade do ensaio e uma diminuição na tensão de alimentação do motor [7].

A Figura 4 apresenta os gráficos para uma corrente de 4,25kA, nestes ensaios todos os corpos de prova se romperam antes do final do ensaio (41ㅇ), muitas vezes se rompendo com o início da aplicação da força. Este fato pode ser constatado observando que as curvas se comportaram sem variação da tensão de alimentação, similares a curva sem carregamento (PADRÃO), ou seja, o movimento do dispositivo ocorreu como se as chapas não estivessem presentes, demostrando que nenhum corpo de prova apresentou resistência que possa ser detectada pelo aparelho. Outro ponto a ser observado é que todos os ensaios possuem tempo total inferior ao ensaio sem carga, sendo este realizado sem carga e, portanto o menor tempo de ensaio possível. Um fator também observado nesse teste é a validação dos dados da Tabela 2 que afirmam que para 4,25kA todos os pontos estão "colados" e dessa forma apresentam baixa resistência, ou seja, curva semelhante à curva padrão.

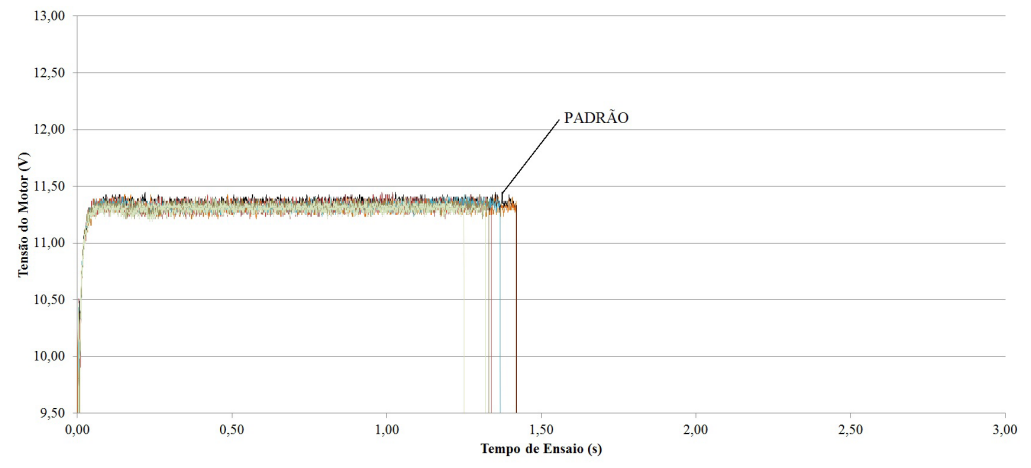

Figura 4. Gráfico do ensaio de torção dos corpos de prova soldados com 4,25kA.

Os pontos soldados com 5,0kA não se romperam durante o ensaio, podendo ser observado uma diferença entre a curva padrão e as curvas apresentadas na Figura 5, demostrando uma resistência à torção. Apesar de o ultrassom afirmar que estes pontos estão "colados" o rompimento não ocorreu durante o ensaio. Este fato pode

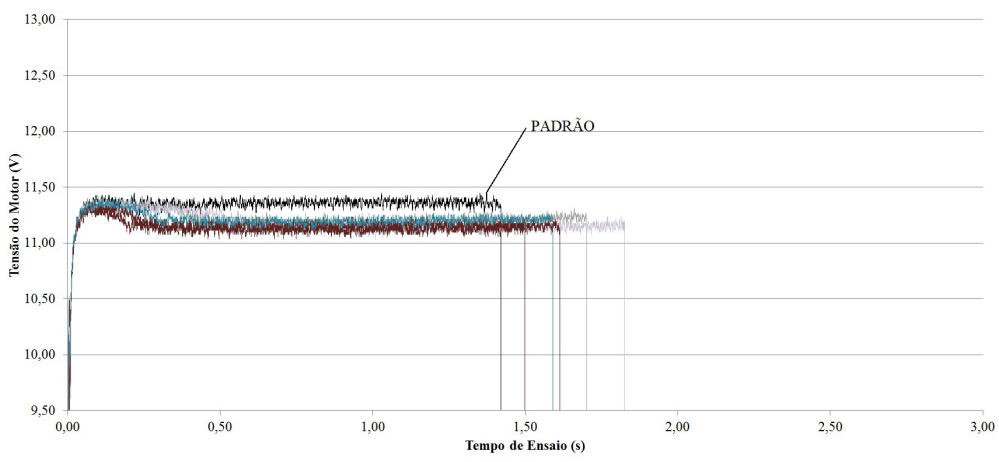

Figura 5. Gráfico do ensaio de torção dos corpos de prova soldados com 5,00kA. 
ser explicado buscando a definição de ponto colado: é um ponto que não se fundiu totalmente ocorrendo apenas fusões localizadas [8]. É esperado que com o aumento da corrente o número de fusões localizadas aumente, porém o ponto ainda é colado segundo o ultrassom, uma vez que ainda existem áreas da interface sem fusão.

Os pontos soldados com 5,75kA não se romperam durante o ensaio e apresentou resistência à torção como demonstra a Figura 6 confirmando a característica apresentada no ensaio de ultrassom (Tabela 2) de ponto bom.

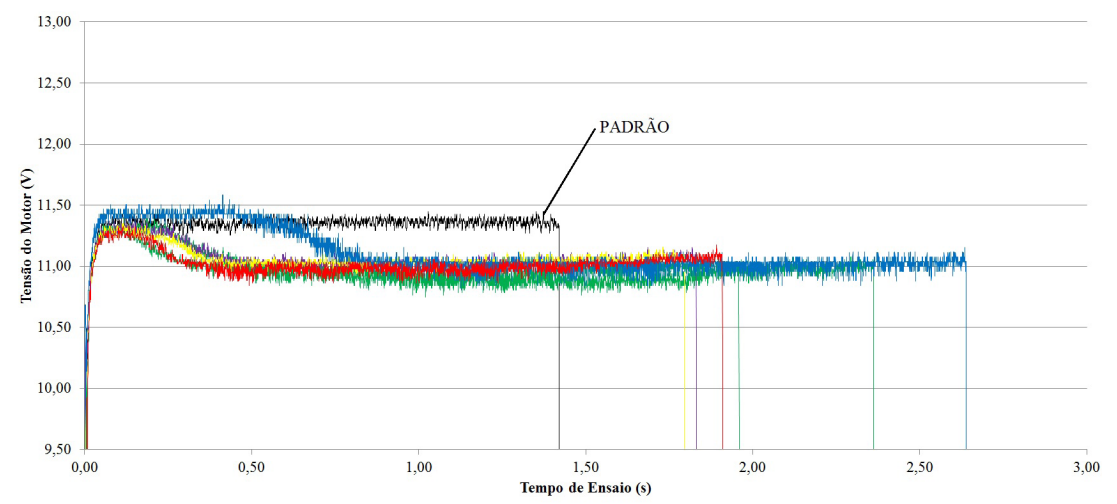

Figura 6. Gráfico do ensaio de torção dos corpos de prova soldados com 5,75kA.

Assim como para avaliação da influência do tempo de soldagem a avaliação da influência da corrente de soldagem no ensaio de torção se deu plotando em um mesmo gráfico as diferentes correntes de soldagem para um mesmo tempo de soldagem. $\mathrm{O}$ aumento da corrente de soldagem promove o aumento do diâmetro do ponto de solda, até um limite em que para correntes e tempos de solda altos ocorre a expulsão de material [1]. Nos ensaios realizados não foi identificado a expulsão de material para nenhum dos parâmetros utilizados. Com o aumento do diâmetro do ponto de solda é esperado um aumento da resistência mecânica do ponto e do torque resistido pelo ponto. $\mathrm{O}$ torque não é diretamente dependente da velocidade do motor, porém ambos são dependentes do fluxo magnético, e por consequência o aumento do torque ocasiona um aumento do fluxo magnético resultando em uma redução da velocidade do motor simultâneo a uma redução da tensão de alimentação [7].

Este fato foi confirmado, pois observando as Figuras 7 a 11, para todos os tempos de soldagem com o aumento da corrente ocorre uma redução na tensão de alimentação do motor. Tendo como referência a escala de tensão, para a corrente de soldagem de 4,25kA a tensão de alimentação do motor é semelhante a um ensaio sem carga (Padrão) em torno de 11,5V. Já para a corrente de 5,0kA tem-se uma tensão de alimentação em torno de 11,2V. Por último para uma corrente de 5,75kA tem-se uma tensão de alimentação de 11,0 V. A diferença total da tensão de alimentação do motor entre os ensaios com corrente de soldagem mínima de 4,25kA e máxima de 5,75kA é de $0,5 \mathrm{~V}$. Esta diferença seria pequena em valores absolutos para se caracterizar um ensaio mecânico, porém, todos os ensaios plotados para uma mesma corrente de soldagem, a parte de estabilidade da curva, região III se estabilizou

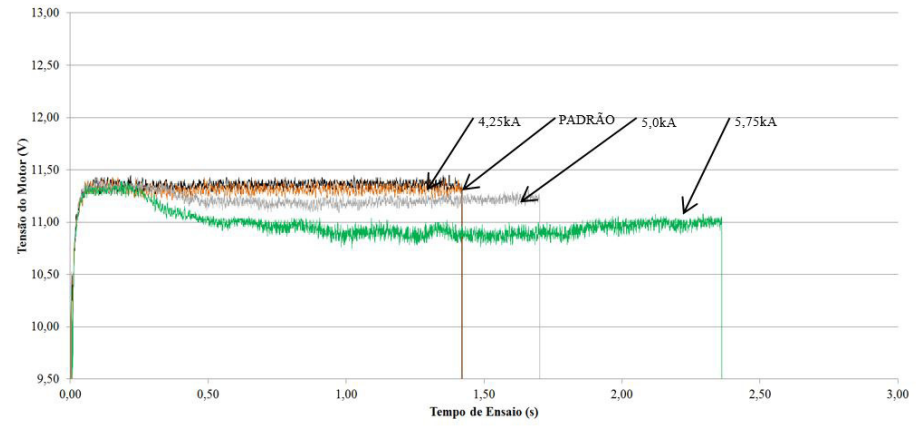

Figura 7. Gráfico do ensaio de torção dos corpos de prova soldados com 10 ciclos. 
Influência dos Parâmetros de Soldagem no Ensaio de Torção de Solda a Ponto em um Dispositivo Automatizado Recém Desenvolvido

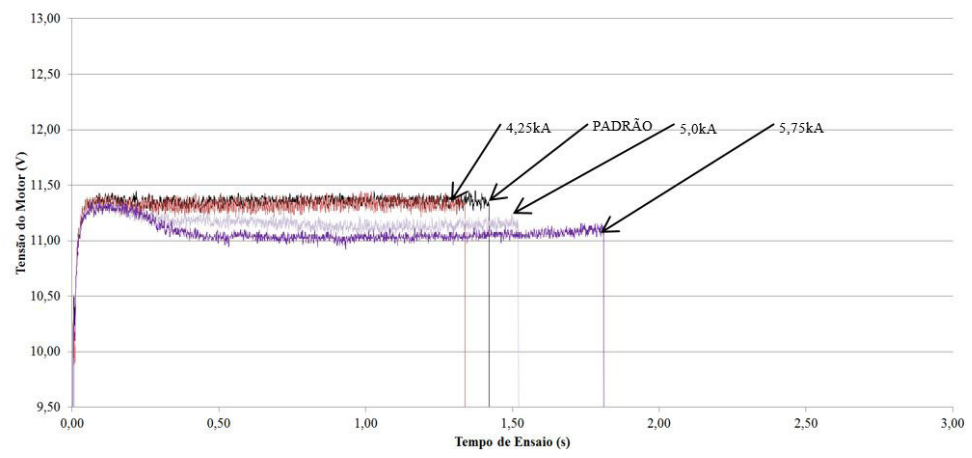

Figura 8. Gráfico do ensaio de torção dos corpos de prova soldados com 30 ciclos.

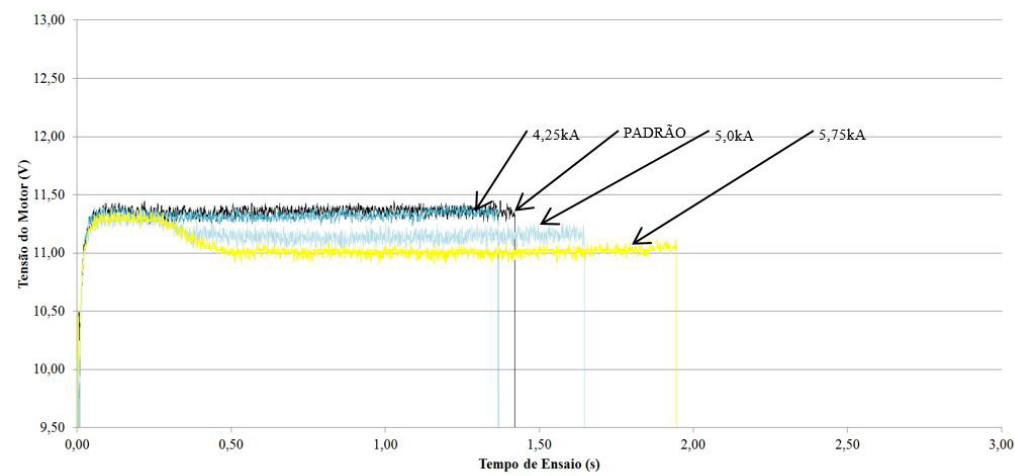

Figura 9. Gráfico do ensaio de torção dos corpos de prova soldados com 50 ciclos.

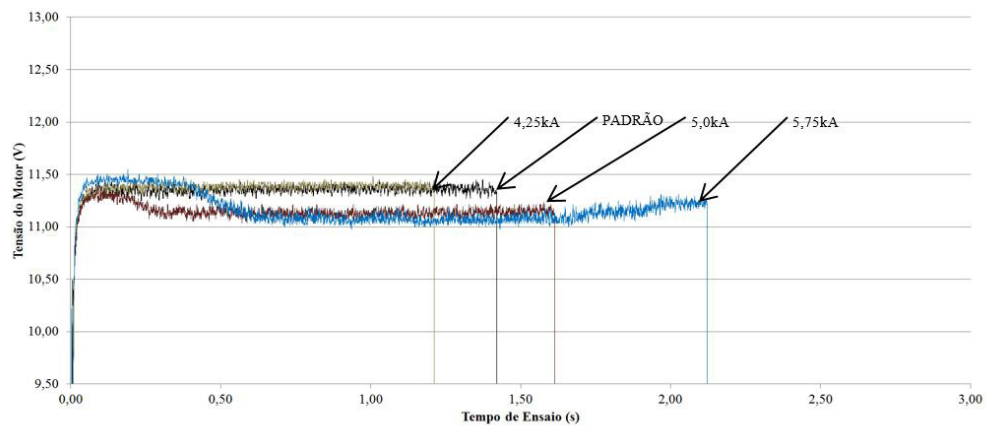

Figura 10. Gráfico do ensaio de torção dos corpos de prova soldados com 70 ciclos.

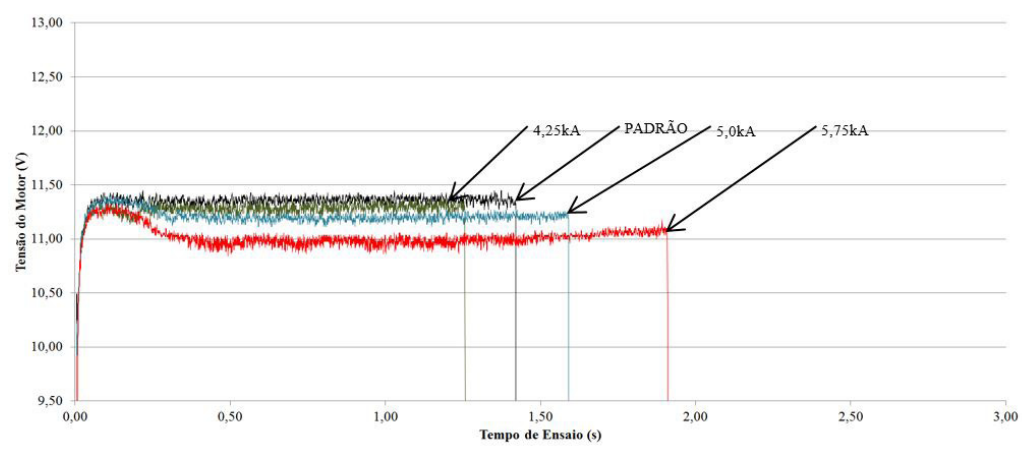

Figura 11. Gráfico do ensaio de torção dos corpos de prova soldados com 90 ciclos. 
para a mesma tensão de alimentação do motor. Esta análise contribui para a afirmação de que há uma diferença mensurável entre os ensaios em que ocorre a variação da corrente de soldagem.

Outro ponto a ser observado é que para o mesmo tempo de soldagem e aumento da corrente de soldagem o corpo de prova de maior corrente resiste por mais tempo ao ensaio confirmando a hipótese de que com o aumento do diâmetro ocorre o aumento da resistência mecânica, aumentando o tempo total do ensaio.

Para certificação dos resultados é necessário garantir que as soldas realizadas com os mesmos parâmetros possuam o mesmo resultado e mais que isso, se o dispositivo tem repetibilidade quando sem carga. Para esta avaliação foram retiradas 3 curvas realizadas ensaiando todo o ciclo do equipamento sem carga e plotado na Figura 12. O gráfico apresenta um perfil semelhante para todos os testes realizados, porém apresenta uma diferença com relação ao tempo total do ensaio, variando aos extremos em torno de $0,3 \mathrm{~s}$.

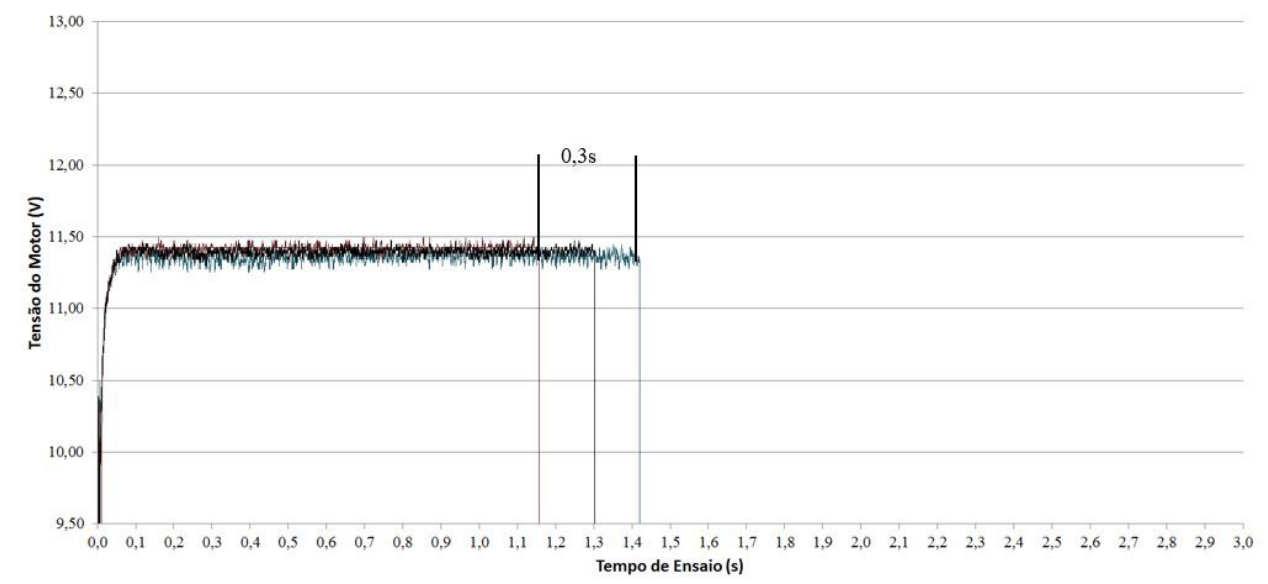

Figura 12. Gráfico do ensaio de torção realizado sem corpo de prova.

O tempo de resposta de um sensor pode variar de 10 a 100 milissegundos, considerando que o fim de curso utilizado no equipamento é um fim de curso mecânico com atuação por mola uma diferença de 300 milissegundos é aceitável. Além disso, qualquer variação no tempo de resposta do sensor é perceptível à aquisição de dados uma vez que a taxa de aquisição é de $5000 \mathrm{~Hz}$ resultando também nas pequenas variações verticais.

É possível visualizar diferença no tempo total de ensaio nos gráficos realizados para avaliar a influência do tempo de soldagem, porém devido à análise já realizada de que o tempo total do ensaio varia devido ao sensor fim de curso, a diferença observada não pode ser definida como sendo influência do tempo de soldagem. $O$ outro parâmetro estudado é que para o mesmo tempo de soldagem e aumento da corrente de soldagem, o corpo de prova de maior corrente resiste por mais tempo ao ensaio confirmando a hipótese de que com o aumento do diâmetro ocorre o aumento da resistência mecânica e a diminuição da velocidade do ensaio, aumentando o tempo total do ensaio. $O$ trabalho em si buscou avaliar a influência dos parâmetros de soldagem dos corpos de prova nos resultados do ensaio de torção com o dispositivo. Possibilitando a utilização destes parâmetros para a soldagem que será utilizada para a fabricação de longarinas utilizados em outros trabalhos.

\section{Conclusões}

Após a preparação dos ensaios, realização dos testes e análise dos dados com base nas referências bibliográficas é possível com este trabalho concluir que:

a) A variação da corrente de soldagem é facilmente percebida nas curvas obtidas do ensaio de torção uma vez que com o aumento da corrente ocorre uma queda na tensão estabilizada de alimentação do motor. 
Influência dos Parâmetros de Soldagem no Ensaio de Torção de Solda a Ponto em um Dispositivo Automatizado Recém Desenvolvido

b)O ensaio de torção automatizado e instrumentado não apresentou sensibilidade à variação do tempo de soldagem, sendo que todas as curvas se comportaram aproximadamente da mesma forma com a variação deste parâmetro.

c) A análise do perfil apresentado pela curva e as tensões atingidas no ensaio de tração apresentam repetibilidade e podem ser analisadas quantitativamente, porém o tempo total de ensaio deve ser analisado apenas qualitativamente e quando comparando alterações nos valores de corrente.

d)O ensaio de torção realizado apresentaram resultados que demostram correlação entre os dados gerados pelo ultrassom e os dados apresentados via aquisição de dados do ensaio.

\section{Agradecimentos}

Os autores agradecem o Programa de Pós-Graduação em Engenharia Mecânica e o Laboratório de Robótica, Soldagem e Simulação da UFMG.

\section{Referências}

[1] Pouranvari M. Effect of welding parameters on the peak load and energy absorption of low-carbon steel resistance spot welding. International Scholarly Research Network Mechanical Engineering. 2011;(2011)2011:ID824149. http:// dx.doi.org/10.5402/2011/824149.

[2] Aslanlar S. The effect of nucleus size on mechanical properties in electrical resistance spot welding of sheets used in automotive industry. Materials \& Design. 2006;27(2):125-131. http://dx.doi. org/10.1016/j.matdes.2004.09.025.

[3] Marques PV, MODENESI PJ, BRACARENSEAQ. Soldagem: fundamentos e tecnologia. 3. ed. Belo Horizonte: Editora UFMG; 2009. 363 p.

[4] Branco HLO. Avaliação de capas de eletrodos utilizadas na soldagem por resistência de chapas galvanizadas automotivas [dissertação de mestrado]. Curitiba: Universidade Federal do Paraná; 2004. 116 p.

[5] American Welding Society. Welding Process. 8th ed. Miami: AWS; 1998. (Welding handbook, vol. 2).

[6] Cota BS. Metodologia para ensaio da resistência à torção de solda a ponto por resistência elétrica [dissertação de mestrado]. Belo Horizonte: Departamento de Engenharia Mecânica, Universidade Federal de Minas Gerais; 2015. 144 p.

[7] Kosow IL. Máquinas elétricas e transformadores. Porto Alegre: Editora Globo; 1982.

[8] Doyum AB, Sonat M. Ultrasonic examination os resistance spot welds. Turquia: DGZfP JAHRESTAGUNG Anwendung; 2003. 